\title{
ФИЗИКО-ХИМИЧЕСКАЯ МОДЕЛЬ ПОВЕДЕНИЯ ТИТАНА В ПРОФИЛЕ ВЫВЕТРИВАНИЯ
}

\author{
В. А. Копейкин \\ Ухтинский государственный технический университет, Ухта \\ vkopeikin@ugtu.net
}

\begin{abstract}
Представлены литературные и авторские данные по стандартной свободной энергии ионов и комплексов титана в водном растворе. Для анализа поведения титана в процессе выветривания использован метод физико-химического моделирования на ЭВМ по программе «Селектор». Установлено, что в профиле выветривания (при учете 41 комплекса и иона титана) титан в растворе представлен только одним гидроксокомплексом - Ті(ОН ${ }_{4}{ }^{0}$. Его содержание контролируется растворимостью рутила и составляет $10^{-7}$ моль/л.
\end{abstract}

Ключевые слова: титан, рутил, выветривание, стандартная свободная энергия, моделирование, программа «Селектор».

\section{PHYSICAL-CHEMICAL MODEL OF THE BEHAVIOR OF TITANIUM IN A WEATHERING PROFILE}

\section{A. Kopeikin}

\author{
Ukhta State Technical University, Ukhta
}

The literature and author's data on the standard free energy of ions and titanium complexes in aqueous solution are presented. To analyze the behavior of titanium in the process of weathering we used the method of PC physical and chemical modeling Selector software. We established that in the weathering profile (when accounting for 41 complexes and titanium ion) titanium in solution was represented by only one hydroxocomplex $-\mathrm{Ti}(\mathrm{OH})_{4}{ }^{0}$. Its content was controlled by the solubility of rutile and rated $10^{-7} \mathrm{~mol} / \mathrm{l}$.

Keywords: titanium, rutile, weathering, standard free energy, modeling, Selector software.

\section{Введение}

А. П. Виноградов [1] считал титан «ключом» в оценке генезиса бокситов. Титан позволяет оценить химию латеритного процесса. Ранее [7] дана оценка стандартной свободной энергии Гиббса $\left(\Delta \mathrm{G}_{\mathrm{f}(298)}\right.$ Дж/моль) ионов титана в водном растворе и выявлена несогласованность данных разных авторов.

\section{Методы и подходы}

Поскольку авторы [11] получили значение свободной энергии Гиббса для гидроксокомплекса титана $\mathrm{Ti}(\mathrm{OH})_{4}{ }^{0}$ (p-p) $\left(\Delta \mathrm{G}_{\mathrm{f}(298)}\right.$ Дж/моль $)=-1323274$ Дж/моль на основании экспериментальных данных, то мы принимаем их рекомендацию за основу. Из этой же работы взято значение $\Delta \mathrm{G}_{\mathrm{f}(298)}^{0}$ для аниона $\mathrm{Ti}(\mathrm{OH})_{5}{ }^{-}$.

В публикации Е. В. Школьникова [14] на основе усреднённых данных ряда авторов вычислены логарифмы общих констант устойчивости гидроксокомплексов $\mathrm{Ti}(\mathrm{OH})_{3}{ }^{+}, \operatorname{Ti}(\mathrm{OH})_{2}{ }^{+2}, \operatorname{Ti}(\mathrm{OH})_{3}{ }^{+}, \operatorname{Ti}(\mathrm{OH})_{4}{ }^{0}$. Эти константы нами использованы для расчета стандартной свободной энергии Гиббса первых трёх гидроксокомплексов и катиона $\mathrm{Ti}^{+4}$.

Например, для реакции

$$
\mathrm{Ti}(\mathrm{OH})_{3}{ }^{+}+\mathrm{OH}^{-}=\mathrm{Ti}(\mathrm{OH})_{4}{ }^{0}
$$

логарифм общей константы устойчивости $(\lg \beta)$ будет равен $11.33\left(\lg \beta_{4}=58.65 ; \lg \beta_{3}=47.32\right)$. Отсюда свободная энергия данной реакции составит $11.33 \times 5708=$ $=64672$ Дж/моль и $\Delta \mathrm{G}_{\mathrm{f}(298)}^{0} \mathrm{Ti}(\mathrm{OH})_{3}{ }^{+}=-1101340$ $\left(\Delta \mathrm{G}_{\mathrm{f}(298)}^{0} \mathrm{OH}^{-}=-157262\right.$ Дж/моль).

Аналогично для реакций

$$
\mathrm{Ti}(\mathrm{OH})_{2}^{+2}+\mathrm{OH}^{-}=\mathrm{Ti}(\mathrm{OH})_{3}{ }^{+}
$$

$\lg \beta_{2}=47.32-35.42=11.9$ и $\Delta \mathrm{G}_{\mathrm{f}(298)}^{0} \mathrm{Ti}(\mathrm{OH})_{2}{ }^{+2}=$ $=-876153$ Дж/моль.

$$
\mathrm{Ti}(\mathrm{OH})^{+3}+\mathrm{OH}^{-}=\mathrm{Ti}(\mathrm{OH})_{2}^{+2}
$$

$\lg \beta_{1}=35.42-17.98=17.44$ и $\Delta \mathrm{G}_{\mathrm{f}(298)}^{0} \mathrm{Ti}(\mathrm{OH})_{3}{ }^{+}=$ $=-619343$ Дж/моль.

$$
\mathrm{Ti}^{+4}+\mathrm{OH}^{-}=\mathrm{Ti}(\mathrm{OH})^{+3}
$$

$\lg \beta_{0}=17.98$ и $\Delta \mathrm{G}_{\mathrm{f}(298)}^{0} \mathrm{Ti}^{+4}=-359451$ Дж/моль. Отсюда для реакции $\mathrm{Ti}^{+4}+4 \mathrm{e}=$ Ті стандартный окислительный потенциал $\mathrm{E}^{0}=0.931$ Вольт $\left(\mathrm{E}^{0}=-\Delta \mathrm{G}^{0}{ }_{\mathrm{R}} / \mathrm{nF}[10]\right)$.

В работе [14] рекомендуется значение $\Delta \mathrm{G}_{\mathrm{f}(298)}^{0} \mathrm{Ti}^{+4}=$ $=-349 \pm 9$ кДж/моль $\left(\mathrm{E}^{0}=0.904 \pm 0.023\right.$ Вольт $)$.

В монографии [9] для титана имеются данные только по константам ступенчатой диссоциации сульфатов: $\mathrm{pK}_{1}{ }^{0}=6.33 ; \mathrm{pK}_{2}{ }^{0}=4.75 ; \mathrm{pK}_{3}{ }^{0}=2.43 ; \mathrm{pK}_{1}{ }^{0}=0.17$.

Для реакции

$$
\mathrm{Ti}\left(\mathrm{SO}_{4}\right)^{+2}=\mathrm{Ti}^{+4}+\mathrm{SO}_{4}{ }^{-2}
$$

свободная энергия реакции равна $36132(6.33 \times 5708)$ Дж/моль и $\Delta \mathrm{G}_{\mathrm{f}(298)}^{0} \mathrm{Ti}\left(\mathrm{SO}_{4}\right)^{+2}=-1140042$ Дж/моль.

$\Delta \mathrm{G}_{\mathrm{f}(298)}$ Дж/моль для других сульфатов титана равны: $\mathrm{Ti}\left(\mathrm{SO}_{4}\right)_{2}{ }^{0}=-1911614 ; \mathrm{Ti}\left(\mathrm{SO}_{4}\right)_{3}{ }^{-2}=-2669943$ и $\mathrm{Ti}\left(\mathrm{SO}_{4}\right)_{4}^{-4}=$ $=-3415372$ Дж/моль.

В побочной подгруппе IV группы периодической системы Д. И. Менделеева вместе с титаном находятся также цирконий и гафний, для которых в монографии [9] приводятся данные по константам ступенчатой диссоциации $\left(\mathrm{pK}_{\mathrm{n}}{ }^{0}\right)$ для карбонатов, гидрокарбонатов, хлоридов и фторидов. Для титана таких данных нет.

Анализируя химию подгруппы титана, авторы работы [3] указывают на близкое сходство химических свойств элементов этой подгруппы - титана, циркония и гафния. 


\section{Результаты}

Исходя из предположения, что и у титана могут быть аналогичные комплексы с другими лигандами и константы ступенчатой диссоциации их изменяются аналогично сульфатным, методом аппроксимации (исходя из предположения, что $\mathrm{pK}$ для недостающих лигандов титана будет меняться с тем же шагом, что и для $\mathrm{Zr}$ и Hf) мы определили эти константы (табл. 1, жирный курсив). Например, разница в $\mathrm{pK}_{1}{ }^{0}$ между карбонатными комплексами циркония и гафния составляет 0.03 (11.68-11.65). Такую же разницу мы допускаем и между карбонатными комплексами циркония и титана. Соответственно, $\mathrm{pK}_{2}{ }^{0}$ для титана будет равна 0.02 (9.82-9.80) и $\mathrm{pK}_{3}{ }^{0}$ равна 7.08 (7.10-7.09). Такое же допущение сделано и для гидрокарбонатных, хлоридных и фторидных комплексов титана.

Затем, исходя из констант ступенчатой диссоциации, была рассчитана их свободная энергия (табл. 2).

В таблице 1 приведены значения $\mathrm{pK}_{\mathrm{n}}{ }^{0}$ для $\mathrm{Ti}, \mathrm{Zr}$ и $\mathrm{Hf}$ с другими лигандами $\left(\mathrm{HCO}_{3}^{-}, \mathrm{CO}_{3}^{-2}, \mathrm{~F}^{-}, \mathrm{Cl}^{-}\right)$, свободная энергия которых взята из [9]. Также использовались другие данные [15-17].

В таблице 2 приведены значения стандартной свободной энергии Гиббса $\Delta \mathrm{G}_{\mathrm{f}(298)}$ (Дж/моль) соединений титана, которые были использованы при моделировании.

В качестве породы для физико-химического моделирования процесса выветривания взят базальт [2] (\%): $\mathrm{SiO}_{2}$ - 49.06; $\mathrm{Al}_{2} \mathrm{O}_{3}-15.70 ; \mathrm{Fe}_{2} \mathrm{O}_{3}-5.38 ; \mathrm{FeO}-6.37$; $\mathrm{MgO}-6.17 ; \mathrm{CaO}-8.95 ; \mathrm{Na}_{2} \mathrm{O}-3.11 ; \mathrm{K}_{2} \mathrm{O}-1.52$; $\mathrm{FeS}_{2}-1.00 ; \mathrm{H}_{2} \mathrm{O}-0.50 ; \mathrm{FeTiO}_{3}-1.36 ; \mathrm{CaF}_{2}-0.30$; $\mathrm{NaCl}-0.28 ; \mathrm{CO}_{2}-0.30 . \Sigma=100.00 \%$.
Таблица 1. Значения $\mathbf{p K}_{\mathbf{n}}{ }^{0}$ диссоциации комплексов $\mathbf{T i}, \mathbf{Z r}$ и Нf при $25{ }^{\circ} \mathrm{C}$ и 0.1 МПа

Table 1. The $\mathbf{p K}_{\mathbf{n}}{ }^{\mathbf{0}}$ values of the dissociation of $\mathbf{T i}, \mathbf{Z r}$ and Hf-complexes at $25^{\circ} \mathrm{C}$ and $0.1 \mathrm{MPa}$

\begin{tabular}{|c|c|c|c|c|c|c|}
\hline $\begin{array}{l}\text { Катион } \\
\text { Kation }\end{array}$ & $\begin{array}{l}\text { Hион } \\
\text { nion }\end{array}$ & $\mathrm{pK}_{1}{ }^{0}$ & $\mathrm{pK}_{2}{ }^{0}$ & $\mathrm{pK}_{3}{ }^{10}$ & $\mathrm{pK}_{4}{ }^{a}$ & $\mathrm{pK}_{5}{ }^{0}$ \\
\hline $\mathrm{Ti}$ & \multirow{3}{*}{$\mathrm{SO}_{4}^{-2}$} & 6.33 & 4.75 & 2.43 & 0.17 & - \\
\hline $\mathrm{Z}_{\mathrm{r}}$ & & 6.06 & 4.53 & 2.29 & 0.12 & - \\
\hline $\mathrm{Hf}$ & & 6.05 & 4.53 & 2.29 & 0.12 & - \\
\hline $\mathrm{Ti}$ & \multirow{3}{*}{$\mathrm{OH}^{-}$} & 17.98 & 17.44 & 11.9 & 11.33 & \\
\hline $\mathrm{Zr}$ & & 14.30 & 12.00 & 10.60 & 9.40 & 7.70 \\
\hline $\mathrm{Hf}$ & & 13.75 & 11.85 & 10.40 & 9.30 & 7.50 \\
\hline $\mathrm{Ti}$ & \multirow{3}{*}{$\mathrm{CO}_{3}^{-2}$} & 11.62 & 9.78 & 7.08 & - & - \\
\hline $\mathrm{Zr}_{\mathrm{r}}$ & & 11.65 & 9.80 & 7.09 & - & - \\
\hline $\mathrm{Hf}$ & & 11.68 & 9.82 & 7.10 & $=$ & - \\
\hline $\mathrm{Ti}$ & \multirow{3}{*}{$\mathrm{HCO}_{3}{ }^{-}$} & 3.30 & 2.81 & 2.06 & 1.36 & - \\
\hline $\mathrm{Zr}$ & & 3.32 & 2.82 & 2.08 & 1.37 & - \\
\hline $\mathrm{Hf}$ & & 3.34 & 2.83 & 2.10 & 1.38 & - \\
\hline $\mathrm{Ti}$ & \multirow{3}{*}{$\mathrm{Cl}^{-\prime}$} & 1.49 & -0.10 & -0.6 & -2.02 & - \\
\hline $\mathrm{Zr}$ & & 1.57 & -0.10 & -0.67 & -2.02 & - \\
\hline $\mathrm{Hf}$ & & 1.65 & -0.10 & -0.67 & -2.02 & - \\
\hline $\mathrm{Ti}$ & \multirow{3}{*}{$\mathrm{F}^{-}$} & 9.31 & 7.29 & 5.00 & 4.00 & 2.80 \\
\hline $\mathrm{Zr}$ & & 9.80 & 8.08 & 6.00 & 5.00 & 4.00 \\
\hline & & 10.29 & 8.87 & 7.00 & 6.00 & 5.20 \\
\hline
\end{tabular}

Таблица 2. Значения стандартной свободной энергии Гиббса $\Delta \mathbf{G}_{\mathrm{f}(298)}$ Дж/моль для соединений титана

Table 2. The values of the standard free Gibbs energy $\Delta \mathbf{G}_{\mathbf{f}(298)} \mathbf{J} / \mathbf{m o l}$ for titanium compounds

\begin{tabular}{|c|c|c|c|c|c|}
\hline $\begin{array}{l}\text { Ион. минерал } \\
\text { Ion. mineral }\end{array}$ & $\begin{array}{c}\Delta \mathrm{G}_{\mathrm{f}(298)}^{0} \\
\mathrm{I} \mathrm{K}_{\mathrm{MOTh}} \\
\mathrm{J} / \mathrm{mol}\end{array}$ & $\begin{array}{l}\text { Ион. минерал } \\
\text { Ion. mineral }\end{array}$ & $\begin{array}{c}\Delta \mathrm{G}_{\mathrm{f}(298)}^{0} \\
\int \mathrm{K} / \mathrm{MaTh} \\
\mathrm{J} / \mathrm{mol}\end{array}$ & $\begin{array}{l}\text { Ион. минерал } \\
\text { Ion. mineral }\end{array}$ & $\begin{array}{c}\Delta \mathrm{G}_{\mathrm{f}(298)}^{0} \\
\mathrm{JW} / \mathrm{MOJh} \\
J / \mathrm{mol}\end{array}$ \\
\hline $\mathrm{H}_{2} \mathrm{O}$ & -237141 & $\mathrm{TiF}^{+3}$ & -694343 & $\mathrm{TiCl}_{3}{ }^{+}$ & -757431 \\
\hline $\mathrm{Ti}^{+4}$ & -354451 & $\mathrm{TiF}_{2}{ }^{+2}$ & -10117705 & $\mathrm{TiCl}_{4}{ }^{0}$ & -877191 \\
\hline $\mathrm{TiOH}^{+3}$ & -619343 & $\mathrm{TiF}_{3}^{+}$ & -1327996 & $\mathrm{Ti}(\mathrm{OH})_{3} \mathrm{Cl}^{0}$ & -1237653 \\
\hline $\mathrm{Ti}(\mathrm{OH})_{2}{ }^{12}$ & -876153 & $\mathrm{TiF}_{4}{ }^{0}$ & -1632579 & $\mathrm{TiCO}_{3}{ }^{12}$ & -953761 \\
\hline $\mathrm{Ti}(\mathrm{OH})_{3}{ }^{+}$ & -1101340 & $\mathrm{TiF}_{5}^{-}$ & -1930312 & $\mathrm{Ti}\left(\mathrm{CO}_{3}\right)_{2}{ }^{0}$ & -1537568 \\
\hline $\mathrm{Ti}(\mathrm{OH})_{4}^{0}$ & -1323274 & $\mathrm{TiF}_{6}{ }^{-2}$ & -2276629 & $\mathrm{Ti}\left(\mathrm{CO}_{3}\right)_{3}^{-2}$ & -2105964 \\
\hline $\mathrm{Ti}(\mathrm{OH})_{5}$ & -1457876 & $\mathrm{Ti}(\mathrm{OH})_{3} \mathrm{~F}^{0}$ & -1419222 & $\mathrm{TiHCO}_{3}^{+3}$ & -965157 \\
\hline $\mathrm{Ti}(\mathrm{OH})_{6}{ }^{-2}$ & -1614100 & $\mathrm{TiOF}^{+}$ & -949768 & $\mathrm{Ti}\left(\mathrm{HCO}_{3}\right)_{2}^{+2}$ & -1568066 \\
\hline $\mathrm{TiSO}_{4}^{+2}$ & -1140042 & $\mathrm{TiOF}_{2}{ }^{0}$ & -1253108 & $\mathrm{Ti}\left(\mathrm{HCO}_{3}\right)_{3}^{+}$ & -2166694 \\
\hline $\mathrm{Ti}\left(\mathrm{SO}_{4}\right)_{2}^{0}$ & -1911614 & $\mathrm{TiOF}_{3}{ }^{-2}$ & -1561887 & $\mathrm{Ti}\left(\mathrm{HCO}_{3}\right)_{4}^{0}$ & -2761327 \\
\hline $\mathrm{Ti}\left(\mathrm{SO}_{4}\right)_{3}^{-2}$ & -2669943 & $\mathrm{TiOF}_{4}^{-2}$ & -1848909 & $\mathrm{TiOC}_{2} \mathrm{O}_{4}^{6}$ & -1343482 \\
\hline $\mathrm{Ti}\left(\mathrm{SO}_{4}\right)_{4}^{-4}$ & -3410077 & $\mathrm{TiF}_{4} \mathrm{OH}^{-}$ & -2187813 & $\mathrm{TiO}\left(\mathrm{C}_{2} \mathrm{O}_{4}\right)_{2}^{-2}$ & -2042628 \\
\hline $\mathrm{TiOSO}_{4}{ }^{0}$ & -1392393 & $\mathrm{TiCl}^{+3}$ & -499245 & $\mathrm{TiOCH}_{3} \mathrm{COO}^{+}$ & -1038887 \\
\hline $\mathrm{Ti}(\mathrm{OH})_{3} \mathrm{SO}_{4}{ }^{0}$ & -1623353 & $\mathrm{TiCl}_{2}^{+2}$ & -629963 & $\mathrm{TiO}\left(\mathrm{CH}_{3} \mathrm{COO}\right)_{2}{ }^{0}$ & -1423815 \\
\hline $\begin{array}{l}\mathrm{TiO}_{2} \\
\text { aнaта3 / anatase }\end{array}$ & -883259 & $\begin{array}{l}\mathrm{TiO}_{2} \\
\text { рутил / rutile }\end{array}$ & -888951 & $\begin{array}{l}\mathrm{FeTiO}_{3} \\
\text { ильменит / ilmenite }\end{array}$ & -1158173 \\
\hline
\end{tabular}

Процесс физико-химического моделирования на ЭВМ детально разобран в работах [5, 12].

Профиль выветривания базальтов представлен на рисунке.

Начиная с самой верхней части профиля, от $\mathrm{p}[\mathrm{W} / \mathrm{R}]$, равного 6 (соотношение «вода - порода» $=1000000: 1$ [Water/Rock]), титан в растворе существует только в виде одного нейтрального гидроксокомплекса Тi $(\mathrm{OH})_{4}{ }^{0}$. Других ионов титана практически нет. Растворимость рутила на всём интервале $\mathrm{pH}$-профиля составляет $10^{-7}$ моль/л
(И. К. Карпов, автор метода физико-химического моделирования на ЭВМ и программы «Селектор» [5] для соотношения «вода - порода» использовал обозначение pu).

Верхняя часть профиля выветривания (на бокситовых месторождениях это зона кирасы) представлена парагенезисом «рутил + гётит + гиббсит», который наблюдается до уровня $\mathrm{p}[\mathrm{W} / \mathrm{R}]=4.15$. Зона «рутил + гётит + гиббсит + каолинит» начинается с $\mathrm{p}[\mathrm{W} / \mathrm{R}]=4.55$. Ниже отметки 4.15 гиббсит исчезает, здесь кончается боксит как руда. 
В процессе моделирования можно менять соотношение «вода - порода». По мере увеличения количества растворённой породы в профиле исчезает гиббсит и появляется каолинит (зона p[W/R] 4.55 до 3). До границы смены окислительных условий на восстановительные наблюдается парагенез - рутил, гётит, каолинит.

Дождевая вода, просачиваясь по профилю выветривания, с верхними минеральными зонами профиля уже практически не реагирует, поскольку всё, что растворимо, вымыто из профиля раньше. К нижним участкам разреза поступает практически свежая дождевая вода. Здесь работает принцип частичного равновесия [8].

Восстановительные условия создавались титрованием атмосферы углеродом при соотношении «вода - порода» $1000: 1(\mathrm{p}[\mathrm{W} / \mathrm{R}]=3)$. Здесь проходит геохимический барьер смены окислительных условий на восстановительные, который четко фиксируется изменением минерального состава и параметров Еh и $\mathrm{pH}$.

Смена окислительных условий на восстановительные отмечается скачком $\mathrm{pH}$ и особенно четко - резким изменением параметра Eh, который приобретает отрицательные значения (см. рисунок).

Минеральный парагенезис в восстановительных условиях профиля выветривания представлен рутилом, пиритом, кремнезёмом, каолинитом, сидеритом, кальцитом, иллитом и бейделлитом.

Зона «рутил + гётит + каолинит» окрашена гидроокислами железа в красно-рыжий цвет и прослеживается до границы смены окислительных условий профиля выветривания на восстановительные. Эта граница четко вид- на по сероватому цвету пород, поскольку железо в восстановительных условиях входит в состав пирита, сидерита и новообразованных смешанослойных алюмосиликатов, представленных иллитами и бейделлитами разного состава. Присутствует также кремнезём и карбонаты (кальцит и доломит). Красящей рыжей окраски оксидов железа здесь нет. Рутил, поскольку его растворимость $10^{-7}$ моль/л, присутствует в профиле выветривания по всему разрезу и сохраняется в дальнейшем при переносе в эрозионном процессе.

Аналогичная модель поведения олова в профиле выветривания приведена в работе [6].

\section{Выводы}

Таким образом, физико-химическое моделирование на ЭВМ поведения титана в профиле выветривания подтверждает постоянное наличие во всём разрезе профиля рутила, начиная с самой верхней его части - с зоны кирасы.

Образуется рутил при разрушении в окислительной обстановке ильменита, в котором железо двухвалентно. В коренных породах, подверженных выветриванию, возможен, конечно, и первичный рутил.

В итоге образуется лейкоксен, в состав которого рутил входит совместно с кремнезёмом и железом [4, 13]. Растворимость рутила на всём интервале рН-профиля составляет $10^{-7}$ моль/л. Из всех использованных нами при физико-химическом моделировании возможных ионов и комплексов титана последний в профиле выветривания существует только в виде одного нейтрального гидроксокомплекса $\mathrm{Ti}(\mathrm{OH})_{4}{ }^{0}$.

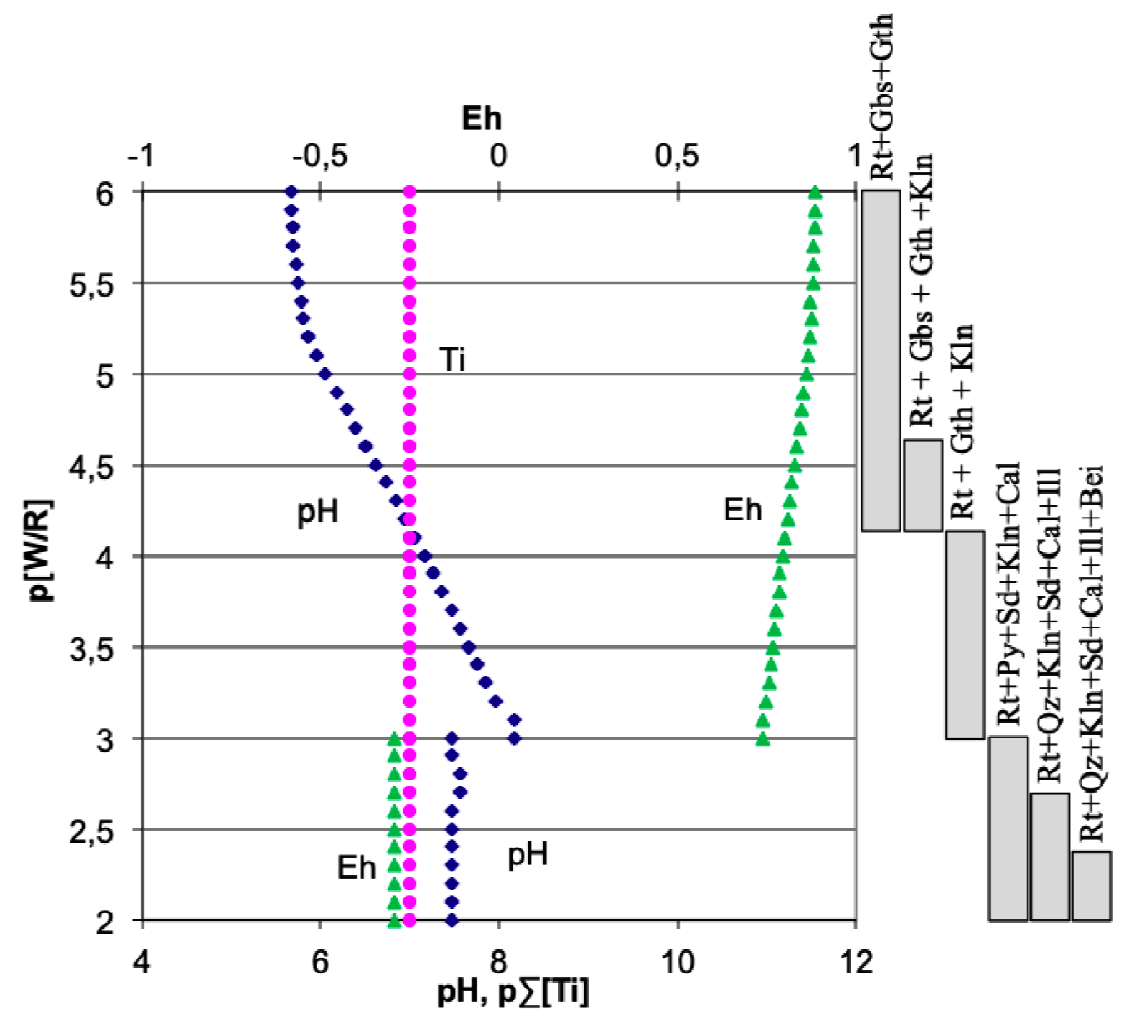

Профиль выветривания базальтов: Gbs - гиббсит, Gth - гётит, Rt - рутил, Kln - каолинит, Ill - иллит, Ру - пирит, $\mathrm{Sd}$ - сидерит, Bei - бейделлит, Cal - кальцит, Qz - кварц (сокращённые названия минералов даны по рекомендации [18]) $\bullet \mathrm{pH}, \Delta \mathrm{Eh}, \bullet \mathrm{p} \sum[\mathrm{Ti}]$

Weathering profile of ilmenite basalts: Gbs - gibbsite, Gth - goethite, Rt - rutile, Kln - kaolinite, Ill - illite, Py - pyrite, Sd - siderite, Bei - beidellite, Cal - calcite, Qz - quartz (abbreviated names of minerals are given on the recommendation [18])

$$
\bullet \mathrm{pH}, \Delta \mathrm{Eh}, \bullet \mathrm{p} \Sigma[\mathrm{Ti}]
$$




\section{Литература}

1. Виноградов А. П. О причинах высокого содержания титана в бокситах // Изв. АН СССР. 1957. Серия геол. № 4. C. 98-103.

2. Войткевич Г. В., Мирошников А. Е., Поваренных А. С., Прохоров В. Г. Краткий справочник по геохимии. М.: Недра, 1977. 184 с.

3. Годнева М. М., Мотов Д. Л. Химия подгруппы титана: сульфаты, фториды, фторсульфаты из водных сред. М.: Наука, 2006. 302 с.

4. Игнатьев В. Д., Буриев И. Н. Лейкоксен Тимана: минералогия и проблемы технологии. СПб.: Наука, 1997. $215 \mathrm{c}$.

5. Карпов И. К. Физико-химическое моделирование на ЭВМ в геохимии. Новосибирск: Наука, 1981. 248 с.

6. Копейкин B. A. Физико-химическая модель поведения олова в профиле выветривания // Геохимия. 2017. № 4. C. $368-371$.

7. Копейкин В. А. Стандартная свободная энергия Гиббса $\left(\Delta \mathrm{G}_{\mathrm{f}(298)}\right.$ Дж/моль) ионов титана в водном растворе // Современные проблемы теоретической, экспериментальной и прикладной минералогии (Юшкинские чтения 2018): Материалы минералогического семинара с международным участием / ИГ Коми НЦ УрО РАН. Сыктывкар: Геопринт, 2018. С. 157-158.

8. Коржинский Д. С. Теория метасоматической зональности. М.: Наука, 1969. 111 с.

9. Крайнов С. Р., Рыженко Б. Н., Швеи В. М. Геохимия подземных вод. Теоретические, прикладные и экологические аспекты. М.: ЦентрЛитНефтеГаз, 2012. 672 с.

10. Наумов Г. Б., Рыжкенко Б. Н., Ходаковский И. Л. Справочник термодинамических величин (для геологов). М.: Атомиздат, 1971. 240 с.

11. Рыженко Б. Н., Коваленко Н. И., Присягина Н. И. Комплексообразование титана в гидротермальных системах // Геохимия. 2006. № 9. С. 950-966.

12. Чудненко К. В. Термодинамическое моделирование в геохимии: теория, алгоритмы, программное обеспечение, приложения. Новосибирск: ГЕО, 2010. 287 с.

13. Швецова И. В. Минералогия лейкоксена Ярегского месторождения. Л.: Наука, 1975. 128 с.

14. Школьников E. В. Влияние полиморфизма и дисперсности диоксида титана на растворимость в кислых и щелочных средах // Известия Санкт-Петербургской лесотехнической академии. 2016. Вып. 215. С. 266-275.

15. Robie R. A., Hemingway B. S., Fisher J. R. Thermodynamic properties of minerals and related substances at $298.15 \mathrm{~K}$ and 1 bar pressure and higher temperatures // Geological survey bulletin 1452. Washington, 1978. $456 \mathrm{p}$.

16. Smith R. H., Martell A. E. Critical stability constants, Vol. 4. N. Y.- L.: Plenum Press. 1977. 156 p.

17. Turner D. R., Whitefield M., Dickson A. G. The equilibrium speciation of dissolved components in freshwater and seawater at $25{ }^{\circ} \mathrm{C}$ and $1 \mathrm{~atm}$ pressure // Geochimica at Cosmochimica Acta. 1981. Vol. 45. No. 6. P. 855-881.

18. Whitney D., Evans B.W. Abbreviations for names of rock-forming minerals // American Mineralogist, 2010. Vol. 95. P. $185-187$.

\section{References}

1. Vinogradov A. P. O prichinah vysokogo soderzhaniy titana $v$ boxitah (Causes of high content of titanium in bauxite). Proceedings of AS USSR, 1957, Series Geol., No. 4, pp. 98-103.
2. Wojtkiewicz G. V., Miroshnikov A. E., Povarennyh A. S., Prokhorov V. G. Kratkii spravochnik po geochimii (Quick reference guide for geochemistry). Moscow: Nedra, 1977, $184 \mathrm{p}$.

3. Godneva M. M., Motov D. D. Himiy podgrupy titana: sylfati, ftoridi, ftorsylfati iz vodnyh sred (Chemistry of titanium subgroup: sulfates, fluorides, fluorsulphates of water environments). Moscow: Nauka, 2006, 302 p.

4. Ignatiev, D. V., Burtsev I. N. Leicokcen Timana: mineralogiy I tehnologicheskii problem (Leucoxene of Timan: Mineralogy and technology problems). St. Petersburg: Science, 1997, $215 \mathrm{p}$.

5. Carpov I. K. Fizico-himicheskoe modelirovanie na EVM in geochimii (Physical-chemical computer simulation in geochemistry). Novosibirsk: Nauka, 1981, 248 p.

6. Kopeikin V. A. Fizico-himicheskay model povedeniy olova in profile vyvetrivaniy (Physical-chemical model of tin behavior in the weathering profile). Geochemistry, 2017. No. 4, pp. 368-371.

7. Kopeikin V. A. Standartnay svobodnay energiy Gibbsa $\left(\Delta \mathrm{G}_{\mathrm{f}(298)} \mathrm{J} / \mathrm{mol}\right.$ ) ionov titana in vodnom pastvure (Standard Gibbs free energy $\left(\Delta \mathrm{G}_{\mathrm{f}(298)} \mathrm{J} / \mathrm{mol}\right)$ of titanium ions in aqueous solution. Modern problems of theoretical, experimental and applied Mineralogy (Jushkinskie read - 2018). Material mineralogical seminar with international participation. Syktyvkar: Komi SC UB RAS, 2018, pp. 157-158.

8. Korzhinsky D. S. Teotiy metasomaticheskoi zonalnosty (Theory of metasomatic zoning). Moscow: Science, 1969, 111 p.

9. Krainov S. R., Ryzhenko B. N., Shvets V. M. Geochimiy podzemnyh vod. Teoreticheskiy, prikladniy I ecologicheskiy aspekty. (Geochemistry of groundwaters. Theory, applied and environmental aspects). Moscow: CentrLitNefteGaz, 2012, 672 p.

10. Naumov G. B., Ryzhenko B. N., Hodokovskiy I. L. Spravochnic termodinamicheskih velichin (dlt geologov) (Reference book of thermodynamic quantities (for geologists)). Moscow: Atomizdat, 1971, $240 \mathrm{pp}$.

11. Ryzhenko B. N., Kovalenko N. I., Prisjagina N. I. Compleksoobrazovanie titana $v$ gidrotermalnih sistemah (Complexation of titanium in hydrothermal systems). Geohimiya. 2006, No. 9, pp. 950-966.

12. Chudnenko K. V. Termodinamicheskoe modelirovanie v geohimii: teoriy, algoritmi, programnoe obespechenie, prilotheniy (Thermodynamic modeling in geochemistry: theory, algorithms, software, applications). Novosibirsk: 2010, Academic publishing house GEO, $287 \mathrm{p}$.

13. Shvetsova I. V. Mineralogiy leikoksena Yaregskogo mestorothdeniy (Mineralogy of leucoxene of Yarega Deposit). Leningrad: Science, 1975, 128 p.

14. Shkolnikov E. V. Vliynie polimorfizma i dispersnosty dioksida titanana na pastvorimost $v$ kislyh I shelochnyh sredah (influence of polymorphism and dispersity of titanium dioxide on the solubility in acid and alkaline media). Izvestia Sankt-Peterburgskoj Lesotehniceskoj Akademii, 2016, is. 215, pp. 266-275.

15. Robie R. A., Hemingway B. S., Fisher J. R. Thermodynamic properties of minerals and related substances at 298,15 $\mathrm{K}$ and 1 bar pressure and higher temperatures. Geological survey bulletin 1452, Washington, 1978, $456 \mathrm{p}$.

16. Smith R. H., Martell A. E. Critical stability constants, V. 4, N. Y.- L.: Plenum Press, 1977, 156 p.

17. Turner D. R., Whitefield M., Dickson A. G. The equilibrium speciation of dissolved components in freshwater and seawater at $25{ }^{\circ} \mathrm{C}$ and $1 \mathrm{~atm}$ pressure. Geochimica at Cosmochimica Acta, 1981, V. 45, No. 6, pp. 855-881.

18. Whitney D., Evans B. W. Abbreviations for names of rockforming minerals. American Mineralogist, 2010, V. 95, pp. 185-187. 